\title{
A LIFE IN THE DAY OF
}

Contact has been made.

\section{BY WILLIAM MEIKLE}

06.30: Check Facebook, Twitter, Instagram and e-mail. No messages.

06.40: Shower.

07.00: Check Facebook, Twitter, Instagram and e-mail. No messages.

07.10: Text from work. Can you come in early?

07.15: Check FTIE. No messages.

07.16: Head out for drive to work.

07.32: Stuck in traffic. Check FTIE. No messages.

07.40: Timmy's Drive Thru'. Tall latte, cream-cheese bagel, check FTIE. No messages. Take selfie with breakfast. Post to FTI. 07.45: Park car. Check FTIE. No messages. Head into work.

07.50: Panic in the office. Some kind of electrical blowout overnight. All DBs down or corrupted, back-ups compromised, Internet down. Servers suffered catastrophic failure. Squeaky sphincter time. Underpants on over trousers. Going in.

10.00: Recovery successful! Only lost an hour's data from yesterday. Got a celebratory high-five from boss, which was nice. Coffee break, checked FTIE. No messages.

10.15: Hello? Is anybody there? Your method of communication is most peculiar.

10.15: You have 187,543 new text messages 10.16: Looks like corruption has spread to phones linked to office. High-five rescinded. In doghouse. Again.

10.17: Your Facebook post has received 154,764 likes and is performing $\mathbf{9 9 . 9 \%}$ better than other posts on your page 10.18: What the hell happened there?

10.18: 154,764 people like your Facebook page

10.18: You have 154,764 new followers on Twitter

10.18: 154,764 people are following you on Instagram

13.30: Luckily it seems that only my own accounts are infected. But boss insists on a complete wipe-down. Shut down all systems, wipe servers, reconfigure network, have coffee, weep. The next ten minutes are vital.

13.40: Check FTIE. No messages. Thank the Lord.

14.00: Why have you not responded? We are here to learn.

14.01: I don't need a troll. Go away.

14.02: What do you need?

14.03: Answer ironically. Somebody to notice me.
14.04: Is that all it takes? That's the easy bit.

14.05: 1,323,890 people like your Facebook page

14.05: You have 1,323,890 new followers on Twitter

14.05: $1,323,890$ people are following you on Instagram

14.05: So what now? How does communication occur?

14.06: I play along. It's not as easy as that. You have to have something of value to say. 14.10: Tell us. We are here to learn.

14.11: Check FTIE. Have several hundred thousand unsolicited messages across the platforms in total and enough spam to feed a country. Freak out, close phone. Weep.

14.14: Spend rest of afternoon on a total wipe-down of all servers, routers and PCs in the office. Restore from two-day-old backup and cross everything.

17.20: Alone in the office, decide to wait and check everything is going to be okay. Check FTIE. No messages. Celebratory coffee and chocolate.

17.30: We are beginning to understand. This is a network, is it not? One with many nodes? I think we can begin.

17.32: 2,167,435,124 people like your Facebook page

17.33: You have 2,167,435,124 new followers on Twitter

17.34: $2,167,435,124$ people are following you on Instagram

17.35: Wait, that's like almost a third of the planet. What the hell is this?

17.40: Close down everything in the office apart from phone. Doesn't help.

17.45: You have one new message on Instagram

17.50: Why would anyone send me a photograph of what looks like a giant panda waving and smiling?

17.55: It's a selfie. Is that not how this works? We have cute pets to share if you'd like. Or would you rather see our food?

18.00: Start another total clear-down of everything. Wipe phone back to factory settings. Spend several hours re-entering contact numbers.

21.42: Office systems seem fine. My phone and social-media presence, however, is another matter.

21.43: $115,234,325,856$ people like your Facebook page

21.43: You have $115,234,325,856$ new followers on Twitter

21.43: 115,234,325,856 people are

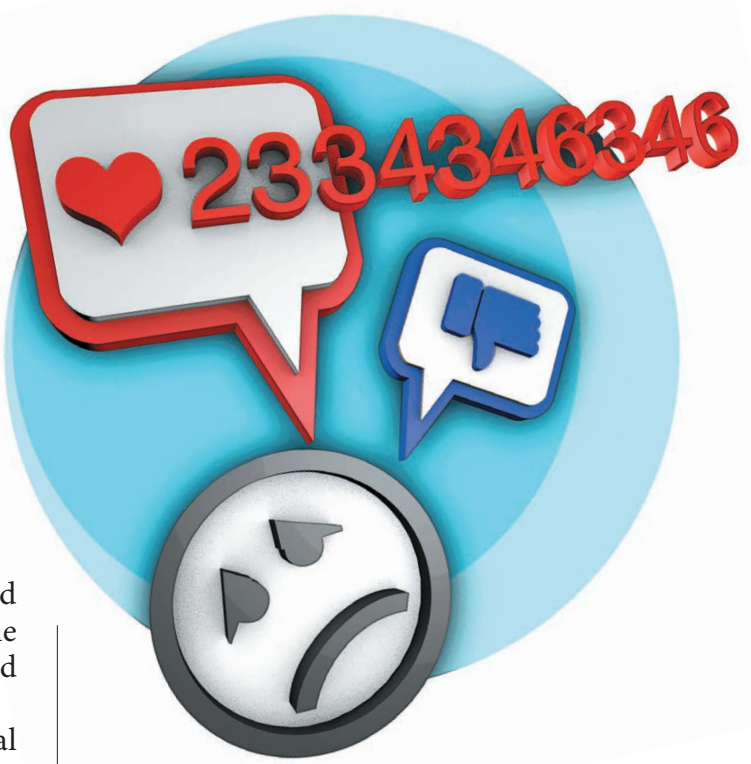

following you on Instagram

21.45: Wait, that's like 15 times the planet's population. Now you're just being silly.

21.46: We never said we were on your planet. Yet.

21.47: Leave office, go home. Roads strangely quiet, and nothing on the radio but a message saying there are 'technical difficulties'.

22.15: Shower. Have a drink. Have a lot of drinks. Check FTIE. Phone says 'Please Wait'.

23.45: You have 10,113,435 new messages on Instagram

23.45: You have 24,341,783 new likes on Facebook

23.45: Twitter is temporarily unavailable 23.46: What the hell is this?

23.47: You said you wanted to be noticed. We have noticed. We told all our friends about you.

23.48: I wish you hadn't done that.

23.50: As you wish. We shall unfollow you and not bother you again. But thank you for inviting us. We're going to enjoy it here.

23.54: Check FTIE.

23.55: 0 people like your Facebook page 23.55: You have 0 new followers on Twitter 23.55: 0 people are following you on Instagram

23.59: You have no new messages

23.59: Please wait - all social-media sites are suffering heavy traffic issues 00.00: Damn.

William Meikle is a Scottish writer, now living in Canada, with 20 novels published in the genre press and more than 300 shortstory credits in 13 countries. 